\title{
Celulite cervical em frangos de corte causada por Escherichia coli
}

\section{Cervical celullitis in broiler chickens for Escherichia coli}

\author{
Benito Guimarães de Brito ${ }^{1 *}$; Claudia Yurika Tamehiro ${ }^{1}$; Werner Okano ${ }^{1}$; \\ Marcia Marinho Luzardo²; Milene Martins Berbel²; Ivens Gomes Guimarães ${ }^{1}$
}

\section{Resumo}

Neste trabalho, relata-se o isolamento de Escherichia coli em frangos de corte apresentando lesão de celulite na região cervical. Foi realizado o isolamento de $E$. coli da lesão de celulite e realizado exames histopatológicos que caracterizaram a lesão. Na epiderme foram verificadas lesões ulcerativas, presença de fibrina na derme e infiltração difusa de linfócitos e heterófilos no tecido subcutâneo.

Palavras chave: Ave; E. coli; Celulite.

\begin{abstract}
In this paper was report the isolation of Escherichia coli in broiler chickens with cellulitis in the cervical region. It was carried through the isolation of $E$. coli of the lesion of cellulitis from broilers and carried through histopathological examination of skin that had characterized the lesion. Focal ulcerations of epidermis, fibrin in dermis and difuse infiltrated by lymphocytes and heterophils on subcutaneous tissues.
\end{abstract}

Key words: Avian; E. coli; Cellulitis.

\section{Introdução}

A celulite aviária, também conhecida como processo infeccioso, processo inflamatório, "waffle skin" e dermatite necrótica, foi descrita, pela primeira vez, na Grã-Bretanha por Randall et al. (1984). A celulite aviária nos últimos anos têm sido uma das principais causas de condenações de carcaças de frangos de corte, sendo considerada uma patologia emergente na avicultura mundial (NORTON, 1997; BRITO ; TAGLIARI, 2000). Somente nos Estados Unidos, na última década, a incidência de celulite aviária aumentou mais de cinco vezes (NORTON, 1997). Estima-se uma perda anual superior a $80 \mathrm{mi}-$ lhões de dólares pela condenação de aves (NORTON; HESS, 1999). No Canadá estima-se que a celulite aviária é responsável pela condenação de 1,2\% dos frangos de corte abatidos (KUMOR et al., 1998). No Brasil, os relatos de condenações por celulite aviária em agroindústrias variam de $0,14 \%$ a $1,4 \%$ (SCUDELLER, 1997; BRITO, 2002). Considerando um índice de condenação de aves no abate de 0,4\%, Alves, Silva e Brito (2002) estimaram que as

\footnotetext{
1 Departamento de Medicina Veterinária Preventiva, Universidade Estadual de Londrina, Caixa Postal 6001, CEP:86.051-970, Londrina-PR, Brasil. E-mail: bgbrito@zipmail.com.br

2 Estagiárias de Iniciação Científica, Alunas do Curso de Medicina Veterinária da Universidade Estadual de Londrina-PR

* Autor para correspondência.
} 
perdas anuais por celulite aviária atingem a soma de 10 milhões de dólares para a avicultura nacional. Neste mesmo estudo foi relatado que as perdas por aerossaculite verificadas em frangos de corte no abate, provocam prejuízos superiores a 10 milhões de dólares por ano.

Nas aves esta lesão é resultante da defesa do organismo contra bactérias patogênicas em áreas que possuem pequena circulação sangüínea. Os materiais restantes do processo infeccioso bactérias vivas e mortas e células brancas mortas permanecem no local até serem eliminados pela ave. Estas lesões aparecem em horas ou dias e podem demorar semanas para serem totalmente reabsorvidas (HESS et al., 2000).

As celulites nas aves são classificadas em dois tipos: I e II, conforme a localização da área afetada e a extensão da lesão (NORTON, 1997). A celulite tipo I ocorre na região ventral da ave e está relacionada com contaminação no incubatório, devido a ocorrência de onfalite. A celulite tipo II ocorre nas outras regiões do corpo da ave e está associada com lesões de arranhões, que ocorrem durante o crescimento da ave, devido a alta lotação usadas nas criações avícolas (NORTON, 1997; MACKLIN; NORTON; MCMURTREY, 1999).

Nas aves a celulite pode ser provocada pela infecção bacteriana que ocorre através de solução de continuidade existente na pele (NORTON, 1997). O freqüente isolamento de E. coli das lesões de celulite (MESSIER et al., 1993; PEIGHAMBARI et al., 1995a) e a posterior reprodução experimental desta patologia a partir da inoculação de amostras de $E$. coli, comprovam que este microrganismo é o responsável por este tipo de lesão (NORTON et al., 1997; GOMIS et al., 1997). No Brasil, o primeiro relato do envolvimento da E. coli como agente etiológico da celulite em frangos de corte foi realizado por Brito et al. (2001). Peighambari et al. (1995b) estabeleceram um escore de lesão de celulite aviária considerando a coloração, o tamanho da lesão e a presença de hemorragias.(Quadro 1).

\begin{tabular}{|l|c|c|c|c|}
\hline PARÂMETRO & \multicolumn{4}{|c|}{ GRAU } \\
\hline & Severo & Moderado & Leve & Ausente \\
\hline Cor & $\begin{array}{c}\text { Amarelo } \\
\text { escuro }\end{array}$ & Amarelo & $\begin{array}{c}\text { Amarelo } \\
\text { claro }\end{array}$ & Normal \\
\hline Tamanho da lesão & $>10 \mathrm{~cm}^{2}$ & $5-10 \mathrm{~cm}^{2}$ & $<5 \mathrm{~cm}^{2}$ & Sem lesão \\
\hline Presença de hemorragia & + & - & - & - \\
\hline
\end{tabular}

Quadro1 - Escore de lesões de celulite aviária.

O objetivo desta comunicação foi relatar o isolamento de E. coli como agente etiológico da celulite cervical em frangos de corte.

\section{Relato do caso}

Foram examinados no Laboratório de Medicina Aviária do Departamento de Medicina Veterinária Preventiva da Universidade Estadual de Londrina, seis frangos de corte com 14 dias de idade, originários de granja de produção de frangos de corte do Estado do Paraná, Brasil. Estas aves eram provenientes de um lote de 12000 fêmeas, com morbidade de $0,1 \%$, que apresentavam dispnéia, torcicolo e aumento de volume da região cervical. As aves foram vacinadas no incubatório contra doença de Marek, Gumboro e varíola aviária. As alterações mais evidentes encontradas durante a necropsia foram a presença de placa de massa caseosa no tecido subcutâneo, de coloração amarelada com tamanho aproximado de três centímetros localizados na região cervical, não foi observado solução de continuidade na pele no local lesado. Este tipo de lesão é classificado de grau moderado segundo a classificação de Peighambari et al. (1995b), Tabela 1.

O exame bacteriológico foi realizado com o auxílio de "swab" estéril coletando material da lesão da pele, e também foram realizadas culturas de fígado, baço, bolsa de Fabrícius, coração, pulmão, rim e timo. Posteriormente os "swabs" foram semeados em ágar sangue e ágar Mac Conkey, cultivados durante 18 horas a $37^{\circ} \mathrm{C}$. Somente na cultura da lesão de pele houve crescimento de colônias com características de E. coli. Foram selecionadas cinco colônias provenientes de diferentes aves, as quais foram 
identificadas presuntivamente pelas características morfológicas e tintoriais e realizada a identificação definitiva de E. coli, segundo Edward e Ewings (1972). As características bioquímicas foram avaliadas nos testes de oxidase, fermentação e oxidação da glicose, em meio para fenilalanina, vermelho de metila, Voges Proskauer, ágar citrato, meio SIM e meio TSI. Estas colônias tiveram o crescimento avaliado frente aos seguintes carbohidratos: ramnose, rafinose, sorbitol, dulcitol, maltose, lactose, manitol, trealose e arabinose. Todas as amostras apresentaram o mesmo biotipo, fermentaram ramnose, sorbitol, dulcitol, maltose, lactose, manitol, trealose, glicose e arabinose.

Foi coletado fragmento da pele, fixados em formalina tamponada a $10 \%$ para avaliação histológica. Os exames histopatológicos para a caracterização da lesão foram feitos pela coloração de hematoxilina/eosina (LUNA, 1968). Foram observadas lesões ulcerativas na epiderme, presença de fibrina na derme e infiltração difusa de linfócitos e heterófilos no tecido subcutâneo.

\section{Discussão}

Este é o primeiro relato de celulite cervical causada por E. coli em frangos de corte no Brasil. Segundo a classificação de Norton et al. (1997), podemos classificar as lesões observadas como celulite tipo I, devido a origem da contaminação e a idade da ave. Apesar de diversos autores terem questionado a ocorrência da celulite tipo I (MACKLIN; NORTON; MCMURTREY,1999; FALLAVENA, 2000; BILGILI, 2001), neste trabalho confirma-se a ocorrência desta forma de celulite, tendo em vista a idade da ave e a provável contaminação das aves no incubatório através do processo de vacinação. Segundo Zavalla (2000), a manipulação das aves, a penetração da pele com agulhas, os arranhões da pele, as lesões nas cristas e barbelas, podem contribuir para penetração de bactérias na pele das aves. As lesões de pele cicatrizam e desaparecem, entretanto as bactérias permanecem no tecido subcutâneo, aonde a fagocitose das bactérias é ineficiente, e os fagócitos encarregados de eliminar a infecção carecem de arsenal bioquímico que está presente nos fagócitos dos mamíferos, isto significa que as infecções tenderão a serem mais crônicas nas aves.

No exame bacteriológico, foi isolado E. coli, o que permite fazermos o diagnóstico da etiologia da celulite. Vários pesquisadores têm relacionado a $E$. coli como o principal agente etiológico da celulite aviária (MESSIER et al., 1993; PEIGHAMBARI et al., 1995a). O isolamento da E. coli foi realizado apenas no local da lesão da pele, o que está de acordo com as observações de Jeffrey, Chin e Singer (1999) que verificaram que determinadas cepas de E. coli quando inoculadas causavam apenas celulite enquanto outras cepas apresentavam um quadro septicêmico. As amostras isoladas apresentaram o mesmo biotipo, portanto pertenciam ao mesmo clone, e provavelmente tiveram a mesma origem de contaminação, que pode ter sido através da vacina ou falha de assepsia no processo de vacinação.

Embora sejam poucos os casos já registrados de contaminações de aves através de vacinas ou do processo de vacinação, é bastante provável que este seja um problema relativamente comum na avicultura. Na prevenção da celulite cervical é importante a adoção de medidas de controle de qualidade dos imunógenos e do processo de vacinação, para que evitem a contaminação bacteriana.

\section{Agradecimento}

A CAPES-PICDT pela concessão da bolsa de doutorado e aos técnicos do Laboratório de Medicina Aviária da UEL pelo apoio laboratorial. 


\section{Referências}

ALVES , C.; SILVA, A.B. da; BRITO, B.G. de. Ocorrência de colibacilose e celulite aviária no abate de frangos de corte. In: CONGRESSO BRASILEIRO DE ESPECIALIDADES EM MEDICINA VETERINÁRIA, 1., Curitiba, 2002. Anais... Curitiba, 2002. p.153. 2002.

BILGILI, S.F. Manejo preventivo de frangos de corte para reduzir perdas com celulite. In: SIMPÓSIO BRASIL SUL DE AVICULTURA, 2., 2001, Chapecó. Anais... Chapecó: Sociedade Catarinense de Medicina Veterinária-Núcleo Oeste, 2001. p.81-86.

BRITO, B.G. de. Colibacilose aviária. Londrina, 2002. Curso sobre diagnóstico de Colibacilose e Salmonelose Aviária. p.11-28.

BRITO, B.G. et al. Celulite em frangos de corte causada por Escherichia coli. Pesquisa Agropecuária Gaúcha, Porto Alegre, v.7, n.1, 2001. No prelo.

BRITO, B.G. de; TAGLIARI, K.C. Celulite aviária por Escherichia coli. UNOPAR Ciêntifica, Londrina, v.2, n.1, p.143-149, 2000.

EDWARD, P.R.; EWINGS, W.H. Identification of Enterobacteriacea. 3.ed. Minneapolis: Burgess Publishers, 1972.

FALLAVENA, L.C.B. Enfermidades da pele e das penas. In: BERCHIERI JR., A.; MACARI, M. Doenças das aves. Campinas: FACTA, 2000, p.37-45.

GOMIS, S.M. et al. Experimental reproduction of Escherichia coli cellulitis and septicemia in broiler chickens. Avian Diseases, Kennett Square, v.41, p.23440, 1997.

HESS, J.B.; Manejo de la celulitis en la granja. Avicultura Professional, Athenas, v.18, n.7, p.12-13, 2000.

JEFFREY, J.S.; CHIN, R.P.; SINGER, R.S. Assessing cellulitis pathogenicity of Escherichia coli isolates in broiler chickens assessed by an in vivo inoculation model. Avian Diseases, Kennett Square, v.43, p.491-496, 1999.

KUMOR, L.W. et al. Cellulitis in broiler chikens: epidemiological trends, meat hygiene, and possible human health implications. Avian Diseases, Kennett Square, v.42, p.285-291, 1998.
LUNA, L.G. Manual of histologic staining methods of the armed force Institute of Pathology. 3.ed. New York: Mc Graw, 1968.

MACKLIN, K.S.; NORTON, R.A.; MCMURTREY, B.L. Scratches as a component in the pathogenesis of avian cellulitis in broiler chickens exposed to cellulitis origin Escherichia coli isolates collected from different regions of the US. Avian Pathology, Compton, v.28, p.573-578, 1999.

MESSIER, S. et al. Focal dermatitis and cellulitis in broiler chickens: bacteriological and pathological findings. Avian Diseases, Kennett Square, v.37, p.839844, 1993.

NORTON, R.A. Avian cellulitis. World's Poultry Science Journal, v.53, p.337-49, 1997.

NORTON, R.A.; BILGILI, S.F.; McMURTREY, B.C. A reproducible model for the induction of avian cellulitis in broiler chickens. Avian Diseases, Kennett Square, v.41, p.422-428, 1997.

NORTON, R.A.; HESS, J.B. Cellulitis in broiler chickens. World Poultry, Doetinchen,

v.15, n.12, p.56-59, 1999.

PEIGHAMBARI, S.M. et al. Characteristics of Escherichia coli isolates from avian cellulitis. Avian Diseases, Kennett Square, v.39, p.116-24, 1995a.

PEIGHAMBARI, S.M. et. al. Escherichia coli cellulitis: Experimental infections in broiler chickens. Avian Diseases, Kennett Square, v.39, p.125-34, 1995b.

RANDALL, C.J. et al. A new skin disease in broilers? Veterinary Record, London, v.114, p.246, 1984.

SCUDELLER, A.C. Levantamento de condenações de carcaça de aves de linha de abate. Londrina : UEL, 1997. Relatório de estágio curricular do curso de graduação em Medicina Veterinária.

ZAVALLA, G. Manejo de problemas locomotores em reprodutoras pesadas. Prevent News, v.3, n.35, p.1-3, 2000. 